Portland State University

PDXScholar

1983

\title{
The needs of older people as seen by themselves and support providers
}

Sarah Movius Schurr

Portland State University

Follow this and additional works at: https://pdxscholar.library.pdx.edu/open_access_etds

Part of the Gerontology Commons, and the Social Work Commons Let us know how access to this document benefits you.

\section{Recommended Citation}

Schurr, Sarah Movius, "The needs of older people as seen by themselves and support providers" (1983). Dissertations and Theses. Paper 3318.

https://doi.org/10.15760/etd.3298

This Thesis is brought to you for free and open access. It has been accepted for inclusion in Dissertations and Theses by an authorized administrator of PDXScholar. Please contact us if we can make this document more accessible: pdxscholar@pdx.edu. 
AN ABSTRACT OF THE THESIS OF Sarah Movius Schurr for the Master of Social Work presented May 19, 1983.

Title: The Needs of Older People as Seen by Themselves and Support Providers

APPROVED BY MEMBERS OF THE THESIS COMMITTEE:
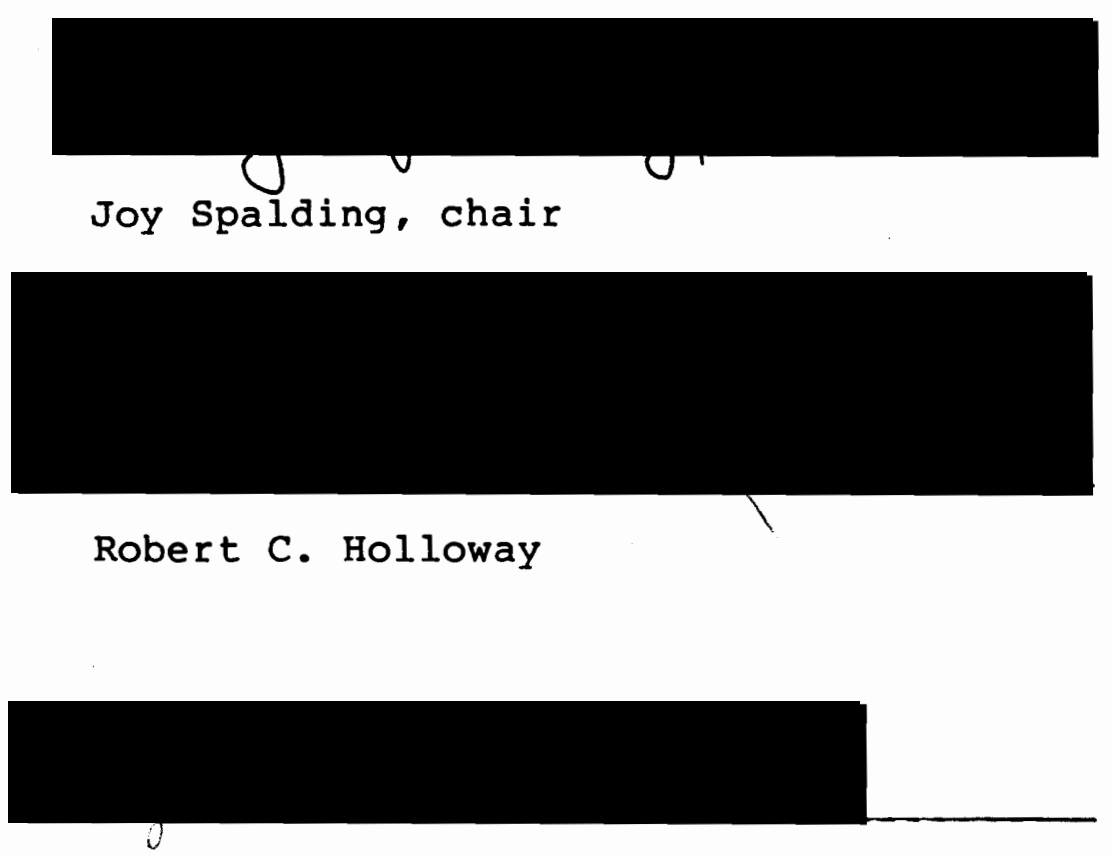

YeVonne Kimmitt

This study compares perceptions of older people's needs from two vantage points: needs as seen by the older people themselves, and the needs of the elders as seen by their family support group. Two hypotheses were examined. The first hypothesis was that the elders and the support 
people would disagree on the needs of the elders. Secondly, the disagreement would be strongest on more abstract needs, like life satisfaction and contact with the opposite sex. The study shows that the perceived needs frequently did not coincide, then assesses the areas of disagreement. The results suggest that services for the elderly should include education programs for their family support providers. In particular, family support providers should be educated in communication skills, and in the needs of elders. By better understanding how older people perceive their own needs, families can better provide the support that elders feel is necessary. 
THE NEEDS OF OLDER PEOPLE AS SEEN BY THEMSELVES AND SUPPORT PROVIDERS

by

Sarah Movius Schurr

A thesis submitted in partial fulfillment of the requirements for the degree of

MASTER OF SOCIAL WORK

Portland State University

1983 
TO THE OFFICE OF GRADUATE STUDIES AND RESEARCH

The members of the committee approve the thesis of Sarah Movius Schurr presented on May 19, 1983.

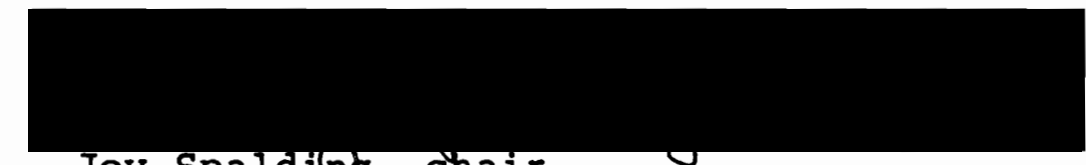

Joy Spalding, Chair

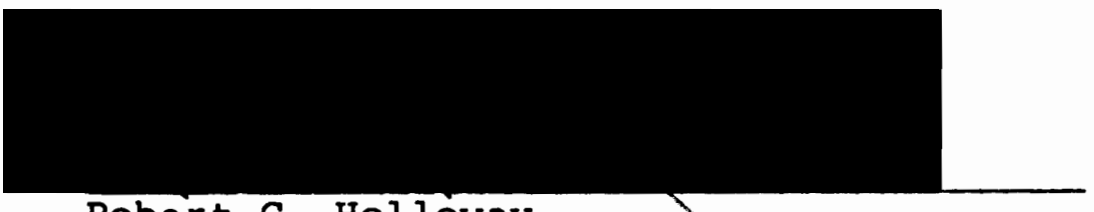

Robert C. Holloway

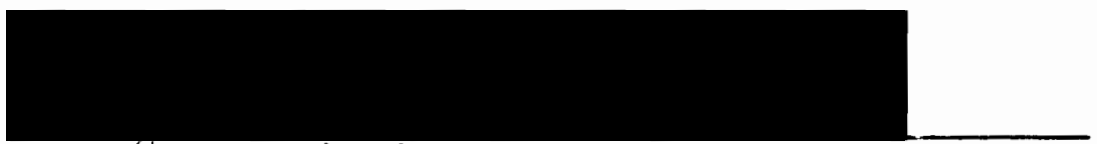

YeVonne Kimmitt

\section{APPROVED :}

Bernard Ross, Dean, School of Social Work

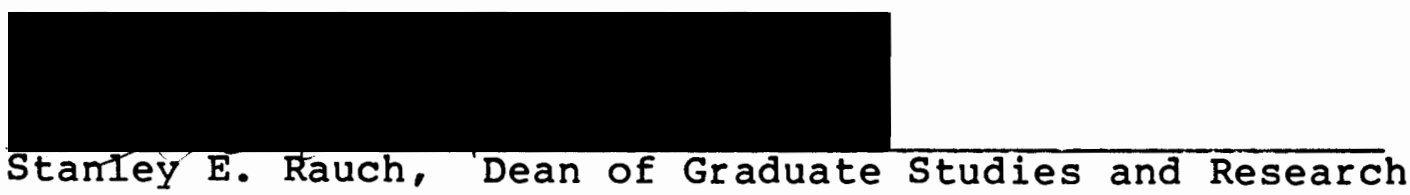


My first thanks go to my thesis committee members, Joy spalding, Bob Holloway and YeVonne Kimmitt. I thank them not only for allowing me the opportunity of a thesis experience, but for their time, energy and support.

I thank the staff and membership of the First Unitarian Church, especially those who helped develop and carry out the interviews. The study never could have been done without their help.

Last, but not least, I thank my husband, Scott. His proofreading and production skills were as valuable as his emotional support. I thank him for his patience and financial support during my entire graduate education. 
TABLE OF CONTENTS

PAGE

ACKNOWLEDGEMENTS .

\section{CHAPTER}

I INTRODUCTION $\ldots \ldots \ldots \ldots \ldots \ldots \ldots \ldots \ldots \ldots \ldots \ldots \ldots \ldots$

II REVIEW OF PERTINENT LITERATURE ........... 3

Family Support .................... 3

Different Perceptions of the Needs of

Older People ................... 5

II METHODOLOGY ...................... 22

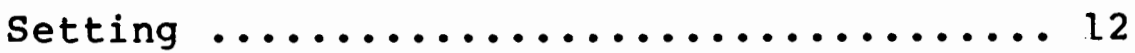

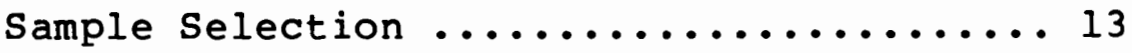

subjects ......................... 14

Instrumentation .................... 15

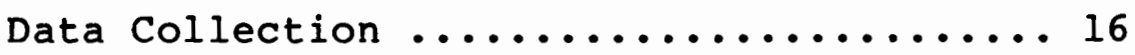

IV $\quad$ RESULTS $\ldots \ldots \ldots \ldots \ldots \ldots \ldots \ldots \ldots \ldots \ldots \ldots \ldots \ldots \ldots \ldots . \ldots \ldots$

Responses of older subjects ........... 18

Comparison of Perceived Needs

Across Groups ................... 22

Comparison of Perceived Needs

Across Pairs .................... 28 
CHAPTER

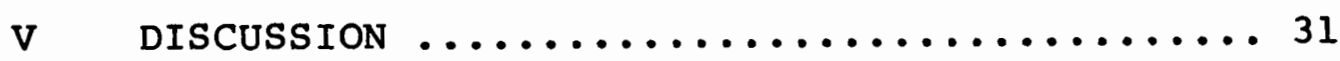

BIBLIOGRAPHY ................................ 39

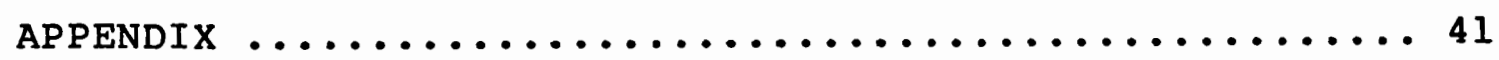




\section{INTRODUCTION}

In order for younger support providers to know what older people $(60+)$ really want or need from them, the younger people must have an understanding of what the older people perceive as their own needs. In this study it will be determined if people who provide support for an older friend or family member perceive the older persons ${ }^{-}$needs the same way the older person does. This study will examine whether the support generation and the older generation agree on the needs of the older generation in this selected sample.

In this study, support providers are not people providing constant physical care to their elders. A support provider may be a family member or friend who aids the older person with instrumental tasks and has an ongoing emotional link with them. They help their older person to meet changing needs. The meeting of these needs helps keep the older person functioning on an independent level in the community .

Such a study has considerable implications for social work practice. With the older population of this country on the $r$ ise and governmental social services decreasing, family and friends are called upon to provide more support for their elders. The results of this study will imply how well family members and friends are able to understand and, based 
on this understanding, to provide for the needs of their elders. This study will assess in what areas needs are not understood. By better understanding what older people perceive their own needs to be, families can better provide the kinds of support which elders see as necessary.

It is hypothesized that there will be some disagreement between the two generations interviewed in this study. Based on the author's work with older people, it is hypothesized that the older people and their support providers agree on basic needs such as medical care, housing or transportation. These are needs which are easily observable or can be described by one person to another. It is hypothesized that the two groups will disagree on the more abstract needs, like life satisfaction, contact with the opposite sex or neighborhood involvement. These are needs which older people are less likely to be able to communicate to a younger family member or friend, due to their abstract and less observable nature. These are also not needs which a support provider would be as likely to ask about during a visit with an older person. Support providers may anticipate these needs more in terms of their own view of old age than from information received from their elder. 


\section{REVIEW OF PERTINENT LITERATURE}

Family Support:

Contrary to popular belief, most older people are not isolated from their younger family members. Most older people live close to at least one child whom they see more than once a month (Troll, 1979). In fact, three out of four older people with children live within one half hour of their children (Shanas, 1979). Of the 818 of all older people who have living children, 808 see their children about once a week (Harris, 1981). It is the children and other family members who most often provide assistance to older people. Even when older people do not have children near by, siblings, nephews, nieces and grandchildren maintain close contact with older family members.

Family members play a major role in interfacing between older people and bureaucracies for the prupose of seeking social services. Sometimes the social services, such as home makers services or home health services, are contacted without the knowledge of the older person (Leach, 1970) •

More than three fifths of the assistance given to older people with tasks such as housework, yardwork, shopping, cooking, and transportation is given by immediate family: spouses, children, children-in-law and grandchildren. Four fifths of the assistance with more personal tasks, such as dressing, bathing, climbing stairs, 
and getting in and out of bed is provided by immediate family members (Powers and Bultena, 1974).

Daughters are the primary source of support to older people who are unmarried. This reinforces the traditional sex role of woman as responsible for caring functions in the family (Brody, 1982). In the Brody study, three fourths of the older women interviewed chose their adult children as their counselor or confidant. They also looked to adult children for help with grocery shopping and financial management. Older people who are bedfast or housebound are two times more likely to live at home than in an institution (Shanas, 1979).

When younger family members are providing assistance themselves, or contacting social service agencies to request assistance for an older family member, these younger family members must have a clear understanding of what their elder sees as a necessary service. When younger family members do not see the needs of the older people in the same way as the older people, the help they provide or services they obtain may not be those desired by the older person. Not seeing needs which are perceived by the older person may result in the elder not receiving help which enables them to remain happy and productive.

Providing help to an older person who sees it as unnecessary will reduce the older person's self esteem and independence. If younger family members have a clear 
understanding of what older people identify as their own needs and how the needs should be met, families may provide appropriate assistance.

Disagreement about needs between older people and their younger support providers may account for the disparity between the social services used by the older people and those identified in planning surveys as social services which older people expect to use (Powers and Bultena, 1974). Social services which older people say they will use may not be those which are contracted by support providers for the older person.

\section{Different Perceptions of the Needs of Older People:}

The difference between how older people and others view the needs of older people has been examined from the perspective of the family, the professional community and the general public. According to one study, older people and their younger family members who live in the same household tend to have a high level of agreement as to the need for assistance of the the households older member (Moss,1975). This study questioned unmarried older people and the family member whom the elder identified as their primary support provider in their household, support provider being one who provides physical care, gives advice and is emotionally supportive. This support person was usually a daughter. 
The questions covered assistance needs in the areas of health care, personal self care, activities of daily living, finances, transportation, psycho-social needs and housing. The older people and their family support providers showed only 298 disagreement in areas where the older people needed help. Moss and her associates defined this as agreement between the two generations. Agreement was found on questions about activities of daily living, transportation, medical care, and shopping. The older people were asked to identify wants in terms of services available in the community. Family support providers were asked to identify which of the services in the community were needed by their older family member. Health care and help with activities of daily living were reported as wants by older people, but not seen as needs by family members. Family support providers tended to report needs in the social sphere while older people did not list these as wants. The exception to this was that older people did want to belong to senior citizen groups, have friendly visitors, and wanted an opportunity to do volunteer work. Older people more frequently reported wants in the area of instrumental assistance where younger family support providers saw needs in the area of social services.

The professional community does not agree with elders about their needs either. In a recent study, Avant and Dresel (1980) compared the opinions of older people and 
social service workers when asked about the needs of older people. The social service workers had a significant degree of agreement with older people. However, when the group of social service workers was broken down into categories, some suprising correlations appeared. Workers with training in gerontology were in less agreement with older people than workers with no training in gerontology. Workers who provide services to all age groups were more in agreement with the older people than the workers who just worked with the elderly. Direct service staff was in less agreement with the older people than was the administration. Therefore, training in gerontology or constant exposure to older people may not guarantee identifying the needs of older people as they themselves do, according to this study. There is a difference of opinion within the professional community as to the needs of the older people. The Danish National Institute on Social Research (Svane, 1972) asked four different parties to assess the needs of each older person in the study. They asked the elders themselves, a volunteer lay interviewer, a welfare worker who had read the nurse's report, and the elders' own doctor. They were questioned about the need for home care or institutionalization. The volunteer interviewers and the older subjects were in agreement in usually seeing a need for home care services. Doctors were the least likely to 
identify needs, and the most likely to recommend institutionalization.

Svane explained these conflicting assessments as being caused by ambiguity in the concept of need. This ambiguity may also account for disagreements in the Moss study and the Avant and Dressel study.

Needs may not be absolute. Though a need is very different than a want, needs and wants are often confused or used interchangeably. A need is something which, if not fulfilled, may lead to an inability to function on an independant level in the community. Un-met needs frequently lead to institutionalization. A want is something which makes functioning more enjoyable, if it is met. What a person perceives as a need may actually be a want. Most of us have some needs, which are not wants.

The literature indicated that involved parties do not always agree on what needs are, so true needs are difficult to define for a client. Perceived needs of one party must be used to judge the validity of others perceived need. "Needs perception, like beauty, vary with the eyes of the beholder" (Little, 1980).

The differences in perceived needs between older people and younger generations may be a function of the view the general public has about how older people view their lives. The general public under the age of 65 has a more negative view of the problems of being old than older people 
do (Harris, 1981). For example, 468 of the general public expected that poor health was a very serious problem for older people, yet only 218 of the people over 65 years of age said if was a very serious problem for them. Only 148 of the older people expressed a need for transportation to shopping and doctor appointments, where 568 of the younger public predicted that this was a need for older people. With rising energy costs, 428 of the older people said they needed help paying their fuel bill to heat their home. However, $81 \%$ of the younger public predicted that that was a need of older people. Subjectively, older people did not view their lot in life any worse than the younger people saw theirs. They did, however, report the same negative view of aging as the general public did. Our society as a whole has a negative view of aging and older people which is not based in fact, but stereotype.

This stereotypic view of being old, not related to reality, would be reflected in how professionals and family support providers see the needs and wants of older people with whom they interact. This may account for the differences in how older people perceive their needs and how others perceive the needs of older people. If older people are identifying their needs as they perceive them and younger people are perceiving the needs of a stereotyped older person, there will be a difference in identified needs. 
Despite the ambiguity of the term "need", needs assessments are done by most local governments to determine how best to serve their older populations. The most comprehensive needs assessment of older people done in the Pacific Northwest was done by the State of Washington in 1978 (Washington, 1978).

older people in Washington are a diverse group. Some areas of need for older people in Washington include money, health and transportation. In 1978, 278 of Washington's older people had a monthly income of under $\$ 300$ for a single person and $\$ 400$ for a couple. When asked what their problems were, 238 of the subjects said that money was either somewhat a problem or a very important problem. Nearly half of the sample had not seen a dentist during the past two years. Thirteen percent of the subjects saw barriers to them getting health care. The most common barrier named was money. Home repairs were seen as a need for 348 of the older Washingtonians. Money was also listed as a barrier to getting home repairs done. Lack of transportation was identified as limiting the activities of 158 of the subjects, with 198 living more than two miles from the nearest bus stop.

The needs of older people are assessed to determine how best to serve older people. However, need is sometimes difficult to separate from want. Perceptions of older people's needs can differ between older people, support 
providers, the professional community, and the general public. Understanding what older people see as their needs is important in providing necessary support. The literature substantiates this. 
METHODOLOGY

Setting:

This study was conducted under the sponsorship and with the cooperation of the First Unitarian Church in Portland. The study was a project of the Committee for Creative Age Concerns of this Church. The Committee for Creative Age Concerns is chaired by Dr. YeVonne Kimmitt, Mr. Allen Hoag and the author. This committee was created and partially funded as part of a pilot project on aging sponsored and by the Unitarian Universalist Service Committee. The Unitarian Universalist Service Committee provided some initial funding for the Portland branch of the pilot project.

The Unitarian Universalist Service Committee pilot project guidelines stress the importance of education, social action and consciousness-raising. The living environment of older people, both in terms of physical housing and quality of life, is the focus of the project. The UUSC also requested the involvement of the generation which provides support for the elderly and is anticipating their own entrance into old age.

This study was initiated with two purposes. The first purpose is to do a general needs assessment among the older members of the congregation. This was not only to determine their material needs, but to assess how well the church was meeting these needs and to determine how the church could 
serve them better in the future. The second purpose in initiating the study was to test the research hypothesis: Do support providers perceive the needs of the elders they care for differently than the elders themselves perceive these? The results of this research could help the committee assess the need for education services for the support providing generation and to plan needed services to older church members.

Sample Selection:

All subjects were located through the First Unitarian Church. The church roster was examined and a list made of all members over the age of 60 years. The church secretary removed from this list the names of those whom she felt would feel great discomfort at being identified as an older member of the church. Those people removed from the list were generally below retirement age. This reduced the original list by about 308. Each of the people on the remaining list of older Unitarians was contacted by telephone. The telephoning was done by church volunteers, members of the Committee for Creative Age Concerns. The nature of the needs assessment and the intergenerational research were explained as well as the study's connection to Portland State University. Potential subjects were then asked if they would be willing to be interviewed. Of the 328 who consented, we asked if they had a support provider in the Portland area whom we could also contact. 
Support provider was defined to them as not necessarily someone who provides financial support or physical care, but also someone with whom you spend time, someone from whom you might ask advice, or someone you would call in an emergency. The names of these support providers were recorded and they were telephoned to request an interview.

This procedure gave us a nonprobability sample of 39 older Unitarians and 15 support providers who could be interviewed. These subjects were assigned to trained volunteer interviewers. The interviewers then contacted the subjects to schedule the interview. Additional subjects were sought through announcements in church publications and at Sunday services. These announcements brought no results. The representativeness of the sample is questionable because of the nature of the sampling procedures.

\section{Subjects:}

All older subjects were members of First Unitarian Church. Some, but not all, of the support providers were church members. In a demographic survey of the church done in 1981, the following information was obtained about the church membership. The church is almost entirely white. Women represent a slight majority over men, at 588 of the membership. It is a well-educated population with 768 of the church members over 18 years of age holding a college degree. In fact, 378 of the membership holds a graduate 
degree. The income of members covers a broad range, with 138 making less than ten thousand and 138 making over fifty thousand.

The older church members interviewed showed similar demographic characteristics. All were white and had completed high school. Most had some college education, if not a degree. $68 \%$ were women. The mean age of the older subjects was 78 , with a range between 67 and 89 . None were institutionalized, though many lived in housing for older people. Only one lived with one of her children. 308 lived with a spouse. 478 were widowed.

The support providers interviewed ranged in age between 31 and 74 , with a mean age of 52 . Like their elders, most hold college degrees. In fact, 368 hold graduate degrees. A slight majority (578) of the support providers were women, with 438 being men. This is a higher proportion of male support providers than expected, based on the literature (Brody, 1982)

\section{Instrumentation:}

The questionnaire used was designed to serve both as a needs assessment tool and a comparison tool. A majority of the questions were taken from the older Americans Status and Needs Assessment Questionnaire published by the U.S Department of Health, Education and Welfare, Administration on Aging (Burkhardt and Lewis, 1975). This is a widely used needs assessment tool which underwent five years of testing 
before its publication. Additional questions were taken from the Harris Poll (Harris,1981). Some questions were created specifcally for this study. The questionnaire included the Branburn Affect Scale (Bradburn, 1969) as a global measure of life satisfaction.

The resulting questionnaire took about one hour to administer. A majority of the questions were at the nominal or catagorical level. The questionnaire covered the areas of housing, transportation, health, neighborhood support, income, employment, life satisfaction, family participation, and the role of the church. It was reviewed by professionals in the areas of gerontology and research.

The data was compiled on a Honeywell $66 / 40$ using the Stastical Package for the Social Sciences. Frequencies were computed for each variable as well as comparisons between variables. A general index of need was computed in the areas of transportation, housing, social role, money, neighborhood support and health using the frequency of need indicating responses on selected questions. These indexes of need were computed to create interval level variables of need for use in statistical comparisons.

\section{Data Collection:}

Interviews were conducted by trained volunteers. These volunteers were members of the Committee for Creative Age Concerns at the First Unitarians Church. Interviewers received three hours of training on interviewing procedures, 
use of the questionnaire and techniques helpful when speaking to older people who may be hard of hearing. Training was done by the author, a clinical psychologist and a physician specializing in gerontology. Ten interviewers were trained. Most of the interviewers were women. They ranged in age from 24 to 60. Many had previous experience in interviewing through careers in education.

Most interviews took place in the subject's home. Occasionally, the subject and interviewer would meet at the church, or some other central location. The interviewer asked the subject questions from the questionnaire and immediately recorded the response. Interviewers were instructed to record narrative responses as well as variable scores. Conversation at the end of the interview was encouraged to reduce anxiety about the interview experience and to gather additional information about the subject. Completed questionnaires were returned to the author for processing. The interviews were done between December 1982 and March 1983. 
RESULTS

Responses of Older Subjects:

The 39 older Unitarians interviewed are a diverse group of people. Therefore, they have a diverse range of needs. This group of older people is in less need of services than the general population of older people usually interviewed in needs assessments. Education has afforded many of them them well paying careers and financial security. Urban living allows greater access to medical and social services than rural older people have. However, need was discovered for some of the sample in the areas of transportation and economics. Needs in other areas were identified as well.

Our sample of older people is made of longstanding community members. Only 98 of the sample said that they had lived in their present neighborhood for less than three years and 508 have lived in their present neighborhood for over 20 years. Though none said all their friends lived inside their neighborhood, 718 said they feel a part of their neighborhood. 348 of our sample belong to some form of neighborhood club or organization. A majority of our subjects, 848 , visit their neighbors more than twice a month. The neighborhood support need seems to be met for most of our subjects.

Most of our sample are very satisfied with their present home. On a five point Leikert scale ranging from 
very satisfied to very dissatisfied, the mean home satisfaction score was 1.2 , between very satisfied and somewhat satisfied. 618 said their home needed no repairs and only $6 \%$ said their homes needed major repairs. When asked if any problems kept them from making needed repairs, most who stated a problem, cited money as keeping them from making these repairs. Most of our subjects, 798, said they did not want to live in housing for the elderly. Housing assistance does not seem to be a need for this group, except perhaps in terms of financial assistance to help with repairs on present housing.

Though 828 of the subjects did have a car in their household, only 568 drive most of the places they go. 168 ride the bus, and 158 ride with family and friends. Many stated that driving and taking the bus at night is difficult for them, so their mobility was decreased after dark. 238 said that they could take the bus none of the places they want to go. Transportation is stated as a problem for $17 \%$ of the subjects. Though this is a comparatively small number of people, the need for transportation can significantly affect an older person's functioning in the community. Transportation is a link between the older person and social activities, family, and employment. An unmet need for transportation can lead to isolation and low self esteem. 
About a quarter of our sample gave a negative response to the question "Is there anything in particular you are looking forward to doing next week"? A negative response to this question is correlated with depression. On a life satisfaction scale ranging from one to five, the mean response was 1.76 , between very satisfied and somewhat satisfied. On the ten point Bradburn Affect Scale, the mean score was 7. Our subjects ranged on the Bradburn from 2, low happiness, to 10 , the highest happiness score.

278 of our subjects said they wanted more companionship with the opposite sex. Because there are more older women than there are older men, opposite sex companionship is more difficult to find for older women than in younger age groups.

Our subjects are a politically active group, with 1008 being registered voters and 678 belonging to some kind of national older peoples organization, like Gray Panthers or AARP. Political activity adds to the self esteem of older people. It impowers people with a sense of power and control (Butler, 1975). Our subjects are concerned politically and generally report high life satisfaction. However, a significant number may be suffering from, or at risk of, depression according to our depression indicator. The most common ways of helping children and grandchildren reported by our older subjects were helping with money, giving gifts, and giving advice on life. 
However, 368 of our subjects said they had no younger people they helped, not even nieces, nephews or friends. Being of service to younger generations in an important social role for older people. Subjects who have no younger people to serve may suffer from an inadequate sense of social role. 888 of those samples have faith in their medical professionals and 918 have as much control over their health care as they would like. Most, 748 , of our subjects say they are well most of the time. Health education is not seen as a need by the older subjects. Compared with others their age, 478 said their health was better than average and 328 said it was about average. Poor health is a problem for some of our subjects, but finding adequate health care is not an identified need. Only 68 of our subjects have trouble getting enough medical care.

Most of the subjects, 858 , are retired and 778 of these have positive things to say about retirement. Only 168 of the subjects want to be employed right now. Most of our subjects have a yearly income between $\$ 10,000$ and $\$ 30,000$ per year, per household. However, 328 have a household income of under $\$ 10,000$ per year. 668 of the subjects say their money meets their needs very well, and only 128 said that they did not have enough money for small luxuries. When asked how they would spend an extra $\$ 20$ a month, 908 listed luxuries like travel, charity, giving it to children, or investments. Only 108 said they would spend 
it on food, clothes or housing. Most of the sample in our study are comparatively well off economically and have few needs in this area. However, some are suffering from economic need.

When a list of social services for older people was read to them, nearly all the subjects were familiar with the services. However, when asked which services they use, it was found that only 10 of the older people in our sample presently make use of any social services specifically for older people. This includes transportation services, meal services, home maker services, recreation centers, visiting nurses and referal services.

\section{Comparison of Perceived Needs Across Groups:}

Among those older people who identified a support provider, and the support providers interviewed for this study, there was agreement as to the needs of the older people on many variables. However, many variables, there was also disagreement between the two groups. Contrary to the research hypothesis, agreement was no greater around observable needs than around abstract needs.

The two groups agreed on whether the older person feels a part of their neighborhood. The support group predicted the older people felt a part of the neighborhood in 738 of the cases, where the older person felt a part of the neighborhood in 678 of the cases. The groups also agreed on whether most of the places the older people go are 
inside the neighborhood (208 vs 278) and if the older people plan to move in the near future (318 vs 278 ). The groups disagreed as to how often the elders visit their neighbors. The support providers anticipated much more visiting, with 678 predicting visits at least twice a week, whereas 478 of the older group visits their neighbors twice a week. The support generation anticipated much less neighborhood involvement in clubs or other neighborhood organizations. Only 78 of the support generation predicted membership in a neighborhood club, where 338 of the elders said they belong to such a club. Although there is agreement between the generations in terms of plans for staying in the neighborhood and a need for neighborhood involvement, the support providers do not seem to understand the social role the elders play in their neighborhoods.

The two groups disagreed on the amount of home satisfaction which the older people have. Only 678 of the support providers anticipated their elder was very satisfied with their present home, where 938 of the olders expressed this high level of home satisfaction. However, 208 of the support providers thought their elder's home was in need of repair; $33 \%$ of the elders saw a need for home repair. Older people in this study are more satisfied with their homes than anticipated by support providers, even though they see the need for more home repairs. 
Both groups agreed that the older person would not like to live in housing just for the elderly, with the support generation predicting a negative response in 698 of the cases and the elders giving a negative response in 698 of the cases.

The support providers, as a group, were in high agreement with their group of elders when asked about the need for transportation assistance. Of the support providers, 278 predicted a transportation need for their elder, where 208 of the elders saw a transportation need for themselves. However, the groups did not agree on the usual mode of transportation used by the older people. Support providers saw the elders as using their own cars to get most places (618). Of the older people, only 408 said they drive most places. Older people mentioned taxis and walking as major modes of transportation. The support providers did not mention taxis or walking as modes of transport usually used by their elders. The two groups disagree very much on the outcome of transportation. Only 538 of the support providers said their elder goes to see family and friends very often, where 738 of the elders said they see family and friends often. The support providers, as a group, seem to agree with the older group on whether transportation needs were met, but not on how they are met or the outcome of this met need. 
The mean scores on the Bradburn Affect Scale (question 32 on the questionnaire) were identical for the two groups (6.4). The scores for some of the individual questions in the Bradburn were also identical. These questions pertained to restlessness, loneliness and feeling "on top of the world". The groups disagreed on other Bradburn questions. 278 of the support providers predicted their elder felt criticized, where only 78 of the elders felt criticized in the past few weeks. On the depression question of the Bradburn Affect Scale many fewer of the support providers (408) anticipated feelings of depression in their older people than reported by the older group, where $67 \%$ felt depressed. The groups did have similar responses on the depression indicator (question 27), with 698 of the support group and 678 of the elders not indicating depression. The support group saw older people wanting assistance in meeting people and doing things in 278 of the cases, where only 78 of the older people expressed this want. Similarly, the support group saw their elders as having enough companionship with the opposite sex in only 778 of the cases, where 938 of the older people with identified support providers had enough contact with the opposite sex. Only 278 of the support providers anticipated their elders being very satisfied with life, where 538 of the older people stated being very satisfied with life. The support providers, as a group, are in agreement with their elders on 
many variables dealing with happiness and social involvement. They may, however, underestimate the general life satisfaction of older people and the older people's ability to meet their own social needs. In spite of this underestimation of life safisfaction, support providers may not recognize serious depression in their older person. When each group was asked in what ways the older people help the younger generations, both groups agreed that advice on life was a primary form of helping. It was mentioned by 578 of the support generation and 508 of the elders. $28 \%$ of the support providers saw advice on child rearing as a way the elders helped the younger generations. Only 78 of the elders mentioned this form of help. In narratives, elders tended to classify advice on childrearing as "interfering". The support providers did not classify this advice as interfering. Being of help to younger generations is important to the self esteem and life satisfaction of older people. Advice is one of the most common ways older people help younger generations. Less frequently mentioned by support providers, but mentioned by elders were forms of financial assistance.

The support providers, as a group, and the older people were in agreement in the area of the elders' health. Among both groups, 408 said the health of the elder was better than average. Of the support providers, 608 said their elder was well most of the time, where 678 of the 
elders said they were well most of the time. Groups agreed that the diet of the elders was good (868 vs 808$)$. Only 78 of the suppport providers, and none of the elders saw any barrier to getting needed health care.

older people tended to see a somewhat smaller need for money than support providers saw. Only 438 of the support providers said the elders' money met their needs very well, where 608 of the elders felt their money met their needs very well. Both groups identified investments and savings as the primary economic priority among the elders.

When asked to identify the most important problems for the older person in question, the support providers identified health care and crime as the most important problems. 408 of the support providers said their elder had been, or has known, a recent crime victim, where only 278 of the elders said they had. The older group identified money and transportation as the most important problems they face. The support providers identify the needs of the elders as health care and protection from crime. The two groups have different perceptions of the most important needs of the older person.

Agreement between the two groups can be tested by comparing the means of key group variables. The mean home satisfaction score among older people with support providers was 1.06 where the score from the support providers was 1.47. When a $T$ Test is used to compare the difference 
between the means, a $\mathrm{p}$ value of .094 is obtained. This indicates the difference is not statistically significant (significance level set at .05). The mean scores on the Bradburn Affect Scale were identical (6.4) for the two groups, though the range was somewhat greater in the older group. The mean life satisfaction score for the older group was 2.36 , where the mean score given by the support providers group was 1.87. There is no statistically significant difference between these two means $(p=.267)$.

On the computed need indexes created for comparison, no significant difference was found between the mean scores in any area of need. Scores were difficult to determine for some of the computed variables, due to a high number of missing cases among the computed variables. If this study were to be expanded, the problem of missing cases could be mitigated to some extent through the use of more highly skilled interviewers. A larger sample size would also help.

\section{Comparison of Perceived Needs Across Pairs:}

There were 14 elder-support pairs across which agreement could be examined on specific variables. When differences in perceived need are examined on a pair by pair basis, variables can be identified where there is agreement and where there is not agreement. There was agreement among 628 of the pairs (8) where both answered the question of whether the elder member was in need of transportation assistance. There was disagreement among 698 of pairs (13 
total) as to how often the elder sees family and friends, a result of transportation use. Within the pairs sampled, the supporting member does not have a high level of agreement with the reported transportation need of the older member. of the 12 pairs who responded to the question, 758 agreed that the older member felt a part of his or her neighborhood. Only 648 of the pairs were in agreement as to whether the elder member, or any of his/her friends, had been a recent victim of crime. Only 618 of 13 pairs agreed on the degree of home satisfaction felt by the older member. An even greater proportion, $758(n=8)$, disagreed on whether the elder's home was in need of repair. There was low agreement among the pairs in this study on the housing need and satisfaction of the elder member. There was slightly more agreement as to how well the neighborhood support need for the elder member was met.

The highest level of disagreement was on the question of whether the older member of the pair had enough social contacts. There was disagreement among 828 of the 11 pairs who responded. There was also disagreement among 788 of the pairs on the Bradburn Affect Scale. Even though the means were identical for the two groups, on a pair by pair basis, this agreement did not hold up. The disagreement was most often in the direction of a lower score from the support provider. There was agreement among $778 \quad(n=13)$ of the pairs on whether the elder member had enough contact with the 
opposite sex. There was also agreement among 858 of the pairs $(n=7)$ on the depression question of the Bradburn. The support providers in this sample do not perceive some of the social needs of their elders the same as the elders.

Agreement among the pairs was mixed on questions concerning health. 578 of the pairs disagreed on whether the elder member has been well most of the time, where $57 \%$ agreed as to how the elder members health compared to that of others his or her age. In this sample, support providers perceive the health needs of the elders in the same was they do about half the time. On the computed health need index, 8 of 11 pairs (728) has scores within three points of each other.

Economic need was an area of some disagreement among the pairs. There was disagreement among $648 \quad(n=11)$ of the pairs as to whether the amount of money the elder members had met their needs well. On the computed index of economic need, 7 of 9 (77\%) had scores within three points of each other. 


\section{DISCUSSION}

This study sampled a well educated population of white, urban and suburban dwellers. For the most part, they expressed little financial need. When asked what could be done to meet their needs, subjects responded with statements like "make me 40 years younger" or "there is nothing that you can do". This group is not asking for social services. When asked what social services they use, it was found that very few use any social services, though they are familiar with them. Narrative responses indicated a resistance to using social services. The needs of this group must be met through means other than traditional social programs such as income maintenance or agency based casework.

The needs deficit of this sample of older Unitarians is much less dramatic than of older people usually studied in needs assessments. Need was apparent in the area of transportation for some subjects. Financial need was indicated by income statistics, though not mentioned as a need by subjects. Depression was mentioned as a problem by subjects and was indicated in some responses to key questions. Though health care was seen as very available for this population, poor health was frequently mentioned as getting in the way of activities.

Change must be made in the image of aging in our society, even among older people. The Harris poll found that society, including older people, had a more negative 
view of being old than was necessary according to selfreports of older people. Likewise, the older sample in this study may have expectations of old age which reinforce a non-active response to problems. Education to promote a more positive view of aging can help older people seek solutions to problems, and perhaps prevent the problems associated with depression: poor physical fitness and social isolation. Social and political action around economic policy, retirement policy and medical research policy can serve this group. The promotion of a more positive view of social service use could serve older people who may be reluctant to seek services.

Family support providers help meet the needs of groups reluctant to use traditional social services. An accurate perception of need is an important aspect of support provision.

In this sample, it was found that there were indeed areas in which support providers saw the needs as the elders did. However, there were areas where they did not. The research hypothesis that there would be more agreement in areas of observable need (for example, housing) than in abstract need (such as feeling control over health care) was not supported in this study. Some abstract needs were seen similarly by support providers and their elders. An example is the elder feeling a part of his or her neighborhood. Some were seen differently, such as home satisfaction. Some 
observable needs were seen similarly, such as transportation need. This was not true for others, such as house repairs. There were some patterns in need agreement. These patterns are more visible in the comparisons between groups than between pairs. Support providers and elders saw the social patterns of the older people in the neighborhood very differently, yet saw the older person's emotional investment in the neighborhood similarly. This indicates an understanding of the emotions of the older person, perhaps with empathy, yet a different understanding of what it means to be the member of a neighborhood. Similarly, support providers were less likely to see a need for repairs in an older person's home than the older person sees, yet support providers are less likely to see a high level of home satisfaction. There appears to be something which makes a home satisfying to the older people other than just its state of repairs. This additional element was undetected by the support providers.

older people and their support providers agreed on when transportation was a problem, but not in how the problem was manifested. Support providers did not know what usual forms of transportation were used, therefore where the deficits lie. The support providers under-estimated how often the older person sees friends or family. This assumption of isolation from family and friends on the part of support providers may be more a function of their guilt 
feelings about their infrequency of visits with their elder than the older person's transportation need.

The support providers assessment of the elders' health seemed fairly close to that of the elder. The agreement was reduced somewhat on the pair by pair analysis. Agreement in this area may stem from the frequency of health as a conversation topic, especially when speaking to older people. A support provider is likely to ask about an elder's health. An older person is likely to give a complete and truthful answer to a support provider. The support providers in this study responded similarly to the non-elderly population in the Harris Poll (1981). Older people were seen as less satisfied with life, lonelier and poorer than the older people saw themselves. The exception in this study was the possibility of depression among older people which may go unrecognized by support providers. The depressed may experience less life satisfaction and feel lonely and deprived.

The results of this study at times can appear confusing and contradictory, especially when comparing the data across groups with the data across pairs. The focus of this research is the family support provision between an older person and his or her support provider, based on the needs of that older person. On a theoretical basis, the paired data address the research hypothesis more directly. Thus these data have more potential for addressing the 
natural support providers interaction with older people. However, this paired data is more difficult to generate than group comparisons. The data comparing specific pairs are more easily rendered unusable due to missing values and human error than grouped data. This is particularly important in a small sample size, as in this study. Comparing across groups also allows for the comparison of means, using T-tests. T-tests provide an objective measure of significance in difference which takes into account sample size and variability. The group comparison data addresses the reseach hypothesis in a less direct fashion, but can be used to compare general differences support providers and their elders.

Considering the large older population of the church, a greater sample size was expected. A high refusal rate resulted in a markedly small sample size. This was especially true for the small number of support providers identified. Older people expressed a reluctance to be classified as an "older person" and were even more reluctant to appear "dependent" on a support person.

Small sample size prevents this data from being as powerful as it could be and concordantly, the results. This sample size, paired with non-random selection make this study not generalizable to the greater population of older people and their support providers. This study does hold 
utility for use in the church and has already begun to inspire service programs

This study can be considered as a first step in broader research development. This study holds many ideas for further research. Further studies could be more generalizable if repeated with a large, random sample using interval level variables for more easy comparison. A church setting does not afford this kind of research due to population size, budget, and staff availability. In a larger sample, perceived need agreement could be compared across variables such as same vs. opposite sex pairs, elderly vs. young support providers or even family dynamic variables.

Another question which could be answered in a larger study is that of the necessity for agreement. This study is based on an assumption that support providers who perceive the needs of their elders the same way the elder perceive them are able to be more effective support providers. This assumption is based on the literature, observations and a belief in client self-determination.

As repeatedly shown in the literature, family support systems provide most of the assistance received by older people. Little has been done to document their effectiveness. Research should be done to address whether older people whose support providers see their needs as they do have have their needs met more readily, have higher life 
satisfaction, or are more likely to avoid institutionalization.

We are assuming that understanding how an older person sees his or her needs is important to being a good support provider. Accordingly, social work can help meet the needs of older people by helping support providers to understand the needs of their elders. As mentioned earlier, dispelling the negative myths of aging can help support providers to see elders as individuals with their own needs, rather than a stereotyped "senior citizen".

On an agency level, or in this case a church level, services can be focused at the support providers rather than the older people. The younger cohort groups are more amenable to social service involvement than are the present population of older people. Services can be based on education. Support providers can be educated as to the needs of older people such as the ones for whom they provide. In this case, that means making the needs assessment reports from this study available to support providers and potential support providers, to help them learn about the perceived needs of older Unitarians. Support providers need to understand the needs of their older person, apart from the group as well. They need to see their elder's individual needs. This means effective communication between older people and their support providers around the areas of need. This can be facilitated 
at the agency level through education in communication skills for older people and/or support providers. Basic communication and listening skills are easy to learn, yet are not known by everyone. These skills could help older people better communicate their perceptions of need to support providers as well as helping support providers to find out how their elders perceive their needs. This improved communication could add richness to other areas of the older person's relationship with support providers as well.

As shown, the perceived needs of older people are not always the same as those needs perceived by a support provider. Perhaps through education and communication the needs of older people can be better understood. With this greater understanding may come more effective service provision to meet those needs and a fuller family life for members of all generations. 
Avant, W. A. and P. L. Dressel. "Perceiving Needs by Staff and Elderly Clients: The Impact of Training and Client Contact". Gerontologist, $1980,20,71-77$.

Bradburn, Norman. The Structure of Psychological WellBeing. Chicago: Aldine Press, 1969.

Brody, E. "The Dependent Elderly and Woman's Changing Roles". Executive Summary from the Philadelphia Geriatric Center, 1982.

Butler, R. N. Why Survive? Being old in America. New York: Harper and Row, 1975.

Burkhardt, J. E. and J. C. Lewis. "The Older American's Status and Needs Assessment Questionaire", prepared by RMC Research Corporation for the Administration on Aging. 1975.

Harris, L. Aging in the Eighties: America in Transition. Washington: The National Council on Aging, 1981.

Leach, J.M. "Counseling with Older People and Their Families". Working With Older People: A Guide to Practice. Washington: U.S Department of Health, Education and Welfare, 1970.

Little, V.C. "Assessing the Needs of the Elderly: state of the Art". International Journal of Aging and Human Development, 1980 , $11: 65-760$.

Moss, M.S. "Needs and Difficulties of Older Persons as Perceived by the Aged and Their Families". Paper presented at the loth International Congress of Gerontology, Jerusalem, Israel, June 1975.

Powers, E.A. and G. L. Bultena. "Correspondence Between Anticipated and Actual Uses of Public Services by the Aged". Social Services Review, 1974, 48(2), 245-55.

Shanas, E. "Social Myth as Hypothesis: The Case of the Family Relations of Old People". Gerontologist, 1979, 19(1), 3-9.

Sussman, M. B. "Family, Bureaucracy, and the Elderly Individual: An Organizational/Linkage Perspective", in Family, Bureaucracy, and the Elderly, ed. Shanas, E. and Sussman, M.B. Durham: Duke University Press, 1977. 
Svane, Ole. "Determining the Needs of the Aged", prepared for presentation at the $3 r d$ International Conference on Social Science and Medicine. Elsinor, Denmark. August 14-18, 1972.

Troll, Lillian et. al. Families in Later Life. Belmont: Wadsworth Publishing, 1979.

Washington State. An In-Depth Analysis of the Needs Assessment of the Elderly-1976. Washington State: Office of Aging, 1978 . 
APPENDIX

SURVEY QUESTIONNAIRE 
MESSAGE TO SUBJECTS

This research is being done by Sarah Movius Schurr both to help the church to better understand older people and their families, and for use as a Masters thesis for the Portland State University School of Social Work.

The purpose of this study is to determine whether younger family members perceive the needs of older people the same way the older people do. Older people and their younger family support providers will both be asked a set of questions about the needs of the older family member. The answers which each generation give will be compared to see how much they agree. All answers are confidential. Your name will not even be on the questionaire. The results will be available in the church library this summer, at the end of the study.

Thank you for this hour of your time. Your participation in this study will not only help our church to plan better ways to assist older people and their families, but will contribute to a larger body of knowledge to help in the formation of programs all over the country.

If you have any questions, please give me a call at a message at the church office.

Thank you again, Sarah Movius Schurr 
I, hereby agree to serve

as a subject in the research project on The Needs of Older People as Seen by Themselves and Their Families conducted by Sarah Movius Schurr.

I understand that the study involves being interviewed and answering questions about needs.

I understand there is no risk associated with this study.

It has been explained to me that the purpose of the study is to learn how older people see their needs and how younger people see the needs of elders.

I may not receive any direct benefit from participation in this study, but my participation may help to increase knowledge which may benefit others in the future.

Sarah Movius Schurr has offered to answer any questions I may have about the study. I have been assured that all information I give will be kept confidential and that the identity of all subjects wil1 remain anonymous.

I understand that I am free to withdraw from participation in this study at any time.

I have read and understand the foregoing information.

Date Signature

If you experience problems that are the result of your participation in this study, please contact the office of Graduate Studies and Research, 105 Neuberger Hall, Portland State University, 229-3423. 
Please tell me these things about yourself.

1. Could you please tell me how old you were on your last birthday?

(age)

2. Do you consider yourself elderly?

yes

no

3. Who lives in this household with you?

Do you (read list: circle all that apply)

live alone

live with spouse

with children

with siblings

with grandchildren

with friends

other (specify)

4. How many of the people in your household, including you, are 60 years old or older?

5. (If not obvious) What is your race of ethnic decent?

White

Black

Oriental

American Indian

Spanish

Other (specify)

6. (do not read) Sex?

male

female

7. What is your marital status now?

married

divorced

separated

widowed

never married

8. How far did you go in school?

(don't read, check appropriate answer)

$0-4$ years

5-8 years

some high school

completed high school

post high school trade school some college

completed college

advanced degree

don't know 
Now I would like to ask a few questions about the home and neighborhood you live in.

9. How long have you been living in this neighborhood?

$$
\begin{aligned}
& \text { less than } 1 \text { year } \\
& 1 \text { to } 2 \text { years } \\
& 2 \text { to } 3 \text { years } \\
& 3 \text { to } 5 \text { years } \\
& 5 \text { to } 10 \text { years } \\
& 10 \text { to } 15 \text { years } \\
& 15 \text { to } 20 \text { years } \\
& \text { over } 20 \text { years } \\
& \text { don't know }
\end{aligned}
$$

10. How often do you visit with your neighbors?

$$
\begin{aligned}
& \text { more than twice/week } \\
& \text { more than twice/month } \\
& \text { once or twice/year } \\
& \text { never } \\
& \text { don't know }
\end{aligned}
$$

11. Do you feel that you are really

a part of this neighborhood, or

do you see it as just a place to live?

$$
\begin{aligned}
& \text { feel a part } \\
& \text { just a place to live } \\
& \text { don't know }
\end{aligned}
$$

12. How many of your friends live in this neighborhood?

Would you say...

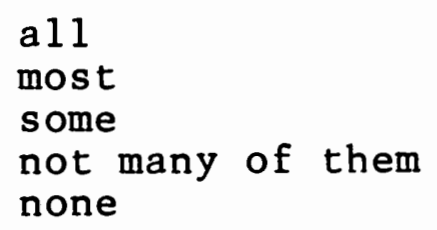

13. Do you belong to any organizations or clubs that are involved with neighborhood activities?

yes

no

don't know

14. Are most of the places you usually go, doctor's office, store, bank, meetings, inside or outside this neighborhood?

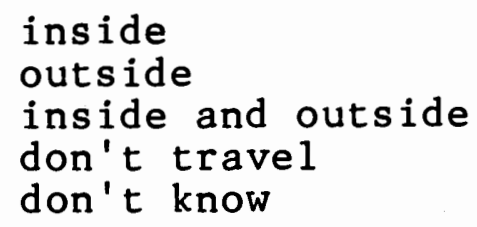


15. Considering everything -- amount of room structure, condition and so forth -- how satisfied are you with your present home?

very satisfied somewhat satisfied neither satisfied nor dissat. somewhat dissatisfied very dissatisfied don't know

16. Do you think the structure of the building you live in needs repairs?

16a. Is there a problem getting repairs done?

needs no repairs needs minor repairs needs major repairs don't know

$16 \mathrm{~b}$. What is the problem?

yes

no

can't afford

physical problem no way to transport material don't know how

landlord won't $\mathrm{fix}$ other

17. Do you plan to move out of this house (apartment) in the next two years?

yes

no

don't know

18. Would you like to live in housing yes just for the elderly?

no

19. Have you or any of your friends been yes victims of a crime around here no recently?

I'd like to ask some questions now about how you get around when you want to go somewhere.

20. Does anyone in this household have a car in working condition?

yes

no

21. How many places that you want to go can you get to using public transportation? (read responses)
all
most
some
a few
none
don't know 
22. How do you usually get around when you want to go somewhere? Do you... (read responses)

walk

drive a car ride with family

ride with friends

take a bus

take a taxi

pay someone to take me other

yes

no

very often

occasiona11y

hardly ever

not at all

enough social contact not enough

yes

no

don't know

enough

not enough

too much

yes

no

yes

no

a problem with transportation other things to do Sunday AM Hard to get out that early no interest other

yes

no

don't know 
29a. Do you have any suggestions on how the church could be more responsive?

30. Are you a member of any local or national organization for yes older Americans? (like AARP)? no

31 Are you registered to vote? yes

no

don't know

32. During the past few weeks, did you ever feel: (repeat "did you ever feel" before each question. *Repeat the whole question before "depressed...")

Pleased about having accomplished something ................. yes Bored .................... yes On top of the world ............. yes Upset because someone criticized you .. yes Particularly excited or interested in something .................... yes no don't know *Depressed or very unhappy ............ yes no don't know

Pleased that things were going your way $\ldots \ldots \ldots \ldots \ldots \ldots \ldots$ yes no don't know

So restless that you couldn't sit long in a chair ..................... yes no don't know

Proud because someone complimented you on something you had done ........ yes no don't know Lonely or remote from other people .... yes no don't know

33. Taking everything into consideration, how would you describe your satisfaction with life in general, at the present time? (read responses)

34. Do you have someone you can call in an energency?

very satisfied somewhat satisfied some satisfied and somewhat dissatisfied somewhat dissatisfied very dissatisfied

yes

no

35. How do you see yourself helping your children and grandchildren? (circle all that apply)

give gifts

care for them when they are ill

babysit grandchildren

help with money

give advice on life shop or run errands fix things around the house give advice on child rearing give advice on housekeeping give advice on business have children live with you other 
Now I'd like to talk about health for a moment.

36. Compared with others your age, would you say your health is:

(read responses)

better than average

about average

worse than average

don't know

37. During the past few years, have

you been well most of the time?

yes

no

38. How many doctors have you seen

in the past year?

no doctors

one

two

three

four

$f$ ive or more

don't know

39. Do you have any problems getting enough medical care?

(if yes, ask 39a)

yes

no

39a. What are the problems?

(circle all that apply)

no doctor in vicinity

can't afford medical care

transportation

don't know where to go can't due to physical cond. other

40. Do you have faith in the doctors and nurses who care for you?

yes

no

41. Do you have as much control over

your health care as you would like? yes

42. Would you like more information about your health in terms of...

medications

nutrition

exercise

sexuality

other (specify)

43. Do you have a good diet?

yes

no

43a. Describe what you usually eat each day. 
44. Who usually prepares your main meal of the day?

self

member of your household friend or relative paid domestic nutrition program restaurant other

45. I'm going to read you a list of things that people usually have to do during the day. After I read each one, please tell me if you can do it alone, with someone to help you, with a mechanical aid or if you can't do it at all.

(mechanical aid = cane, brace, hearing aid, glasses, etc)

dressing and putting on shoes

bathing

cutting toenails

reading

preparing meals

go on walks outside

climb stairs

clean house

hear over phone

shop groceries

ride a bus

drive a car alone with someone alone with someone alone with someone alone with someone alone with someone alone with someone alone with someone alone with someone alone with someone alone with someone alone alone with with someone someone with mechanical with mechanical with mechanical with mechanical with mechanical with mechanical with mechanical with mechanical with mechanical with mechanical with mechanical with mechanical $\operatorname{can}^{\prime} t$ can't can't can't can't can't can't $\operatorname{can}^{\prime} t$ can't can't can't can't

Let's talk about working for a moment.

46. Are you working at a job with pay?

(if yes, ask 46a, if no, ask 46b)

46a. Is it a full or part time

job? (part time=less than 30 hours full time per week)

part time

46b. Would you like to be working?

yes

maybe

no

don't know

47. Do you do volunteer work?

(if no, ask $47 \mathrm{a}$ )

yes

no

47 a. Would you like to do volunteer work if expenses yes were paid? 
48. Are you retired?
(if yes ask 48a)
yes
no

48a. How has retirement been for you?

49. What was your total personal

income over the last 12 months,

before taxes? Was it...(read)

under $\$ 10,000$

$\$ 10,000$ to $\$ 30,000$

over $\$ 30,000$

50. How well does the amount of money you have take care of your needs? (read responses)

very well

fairly well not very well

not at all

51. Do you usually have enough to buy the little extras, that is those small luxuries?

yes

no

52. If you had an extra $\$ 50.00$ a month, what would you spend it on?

food

clothes

housing

car

medical/dental care savings/investments furniture/appliance pay debts

travel/recreation

charity

hire help

give to family

other

53. I am going to read a list of programs

for older people which are provided in some places. I would like to know, for each program, if you have heard of the program.

Home Health Services/visiting nurses Loaves and Fishes/group meals Homemaker services/Geriaids Information and Referral services Recreation groups/Senior Center recreation programs Transportation services for the elderly

$\begin{array}{ll}\text { yes } & \text { no } \\ \text { yes } & \text { no } \\ \text { yes } & \text { no } \\ \text { yes } & \text { no } \\ \text { yes } & \text { no } \\ & \\ \text { yes } & \text { no }\end{array}$


53a. Of these, which ones do you participate in?

home health group meals homemaker services information and referral recreation groups transportation services none

53b. Are you satisfied with what you are getting out of the programs?

home health services group meals homemaker services information and referral recreation groups transportation services

$\begin{array}{ll}\text { yes } & \text { no } \\ \text { yes } & \text { no } \\ \text { yes } & \text { no } \\ \text { yes } & \text { no } \\ \text { yes } & \text { no } \\ \text { yes } & \text { no }\end{array}$

54. I am going to read you a list of areas that people say are problems for older Americans. For each area, please tell me if it is a problem for you. If it is a problem, is it somewhat of a problem or a very important problem?

$\begin{array}{llll}\text { income and money } & \text { no } & \text { some } & \text { very important } \\ \text { health care } & \text { no } & \text { some } & \text { very important } \\ \text { housing } & \text { no } & \text { some } & \text { very important } \\ \text { transportation } & \text { no } & \text { some } & \text { very important } \\ \text { getting more education } & \text { no } & \text { some } & \text { very important } \\ \text { age discrimination } & \text { no } & \text { some } & \text { very important } \\ \text { employment opportunities } & \text { no } & \text { some } & \text { very important } \\ \text { spare time activities } & \text { no } & \text { some } & \text { very important } \\ \text { number of friends } & \text { no } & \text { some } & \text { very important } \\ \text { crime } & \text { no } & \text { some } & \text { very important } \\ \text { nutrition and food } & \text { no } & \text { some } & \text { very important }\end{array}$

54a. Which of these is the most serious problem for you?

55. How do you think this problem might be solved?

THANK YOU FOR YOUR TIME. YOU HAVE BEEN VERY HELPFUL.

(Was there anything unusual about this respondent we should know about?) 